\title{
892.
}

\section{NOTE ON THE ORTHOMORPHIC TRANSFORMATION OF A CIRCLE INTO ITSELF.}

[From the Proceedings of the Edinburgh Mathematical Society, vol. vIII. (1890), pp. 91, 92.]

THE following is, of course, substantially well known, but it strikes me as rather pretty:- to find the orthomorphic transformation of the circle

into itself. Assume this to be

$$
x^{2}+y^{2}-1=0
$$

$$
x_{1}+i y_{1}=\frac{A(x+i y)+B}{1+C(x+i y)} .
$$

Then, writing $A^{\prime}, B^{\prime}, C^{\prime}$ for the conjugates of $A, B, C$, we have

and then

$$
x_{1}-i y_{1}=\frac{A^{\prime}(x-i y)+B^{\prime}}{1+C^{\prime}(x-i y)}
$$

$$
x_{1}^{2}+y_{1}{ }^{2}=\frac{A A^{\prime}\left(x^{2}+y^{2}\right)+A B^{\prime}(x+i y)+A^{\prime} B(x-i y)+B B^{\prime}}{1+C^{\prime}(x+i y)+C^{\prime}(x-i y)+C C^{\prime}\left(x^{2}+y^{2}\right)},
$$

which should be an identity for $x^{2}+y^{2}=1, x_{1}^{2}+y_{1}^{2}=1$.

Evidently $C=A B^{\prime}$, whence $C^{\prime}=A^{\prime} B$; and the equation then is

that is,

$$
1+A A^{\prime} B B^{\prime}=A A^{\prime}+B B^{\prime},
$$

$$
\left(1-A A^{\prime}\right)\left(1-B B^{\prime}\right)=0 \text {. }
$$

But $B B^{\prime}=1$ gives the illusory result

therefore

$$
x_{1}+i y_{1}=B,
$$

$$
1-A A^{\prime}=0
$$

and the required solution thus is

$$
x_{1}+i y_{1}=\frac{A(x+i y)+B}{1+A B^{\prime}(x+i y)}
$$

where $A$ is a unit-vector (say $A=\cos \lambda+i \sin \lambda$ ) and $B, B^{\prime}$ are conjugate vectors. Or, writing $B=b+i \beta, B^{\prime}=b-i \beta$, the constants are $\lambda, b, \beta$; three constants as it should be. 